\begin{tabular}{|c|c|c|}
\hline & Int.J.Curr.Microbiol.App.Sci (2016) 5(10): $91-98$ & \multirow{2}{*}{ 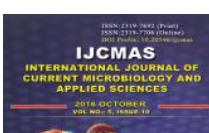 } \\
\hline & \multirow{4}{*}{$\begin{array}{l}\text { International Journal of Current Microbiology and Applied Sciences } \\
\text { ISSN: 2319-7706 Volume } 5 \text { Number } 10 \text { (2016) pp. } 91-98 \\
\text { Journal homepage: http://www.ijcmas.com }\end{array}$} & \\
\hline & & \\
\hline EXCELLENT & & \\
\hline PUBLISHERS & & wwwi.jicmas.com \\
\hline
\end{tabular}

Original Research Article

http://dx.doi.org/10.20546/ijcmas.2016.510.011

\title{
Screening for Nosocomial Pathogens in Stethoscopes, Sphygmomanometers and Mobile Phones of Health Care Providers in a Teritiary Care Hospital
}

\author{
P. Balapriya ${ }^{1 *}$, J. Padmakumari ${ }^{1}$ and A. Vijayalakshmi ${ }^{2}$ \\ ${ }^{1}$ Department of Microbiology, Government Medical College, \\ Omandurar Govt. Estate, Chennai, India \\ ${ }^{2}$ Department of Microbiology, Govt. Chengalpattu Medical College, Chengalpattu, India \\ *Corresponding author
}

Keywords

Health Care

Workers,

Nosocomial

infection,

stethoscopes,

sphygmomano-

meters,

mobile phones.

Article Info

Accepted:

12 September 2016

Available Online:

10 October 2016
A B S T R A C T

The transmission of infections in the hospital (nosocomial infections) from contaminated medical and non-medical devices is a major problem Medical devices and non-medical devices such as stethoscopes, sphygmomanometers and mobile phones play an important role as vehicles and sources of infection. To determine the level of bacterial contamination of medical and non-medical devices used by Health Care Workers $(\mathrm{HCW})$ in a tertiary care hospital. To study the antibiotic susceptibility pattern of the isolates. 150 swab specimens(stethoscope -50 , sphygmomanometer -50 and mobile phones -50 ) handled by Health Care Workers were collected, processed and the isolates were identified. The isolated organisms were subjected to antimicrobial susceptibility testing with Kirby Bauer disc diffusion method as per CLSI Guidelines. 150 devices were tested for the presence of pathogenic microorganisms. Out of which 31 of them contained nosocomial pathogens. 11 out of 50 stethoscopes, 12 out of 50 mobile phones and 8 out of 50 Sphygmomanometer were found to be positive for nosocomial pathogens. Many of the isolated pathogens were resistant to commonly used drugs like cotrimoxazole, gentamycin and ciprofloxacin. 21\% of the 150 (medical and non-medical) devices used by the health care workers contained nosocomial pathogens. This study highlights the importance of stethoscopes, mobile phones and sphygmomanometer as reservoirs of resistant nosocomial pathogens and the associated risk of transmission of nosocomial infections to the patient and to the health care providers themselves. Hence regular screening and development of effective preventive strategies such as regular decontamination of the devices with disinfectant to reduce the burden is of utmost necessity.

\section{Introduction}

Nosocomial infection is an important problem in all modern hospitals. As early as 1846, Ignaz Semmelweiss (Father of Infection Control) paid a great service to medicine and humanity by demonstrating that bacteria was transmitted to patients by contaminated hands of health care workers and had it prevented by the simple measure of washing hands with antiseptic solution (Dennis et al., 1991). 
After 68 years, doctors today use sanitizers even between patients, but what about other devices used? It has long been recognized that stethoscope and other inanimate objects carry virulent microorganisms that can cause Nosocomial infections in susceptible patients. The manner in which these are used has the potential to cause colonization of bacteria and transfer of these bacteria from one person to another (Gopinath et al., 2011).

In the hurried milieu of operating rooms, Emergency departments and Intensive care units, contaminated sphygmomanometers are used routinely and have been identified as potential sources of Nosocomial infection or vehicles of contagion in selected patient population (De Gialluly et al., 2006).

Innovation in mobile communication technology has provided novel approaches to the delivery of health care and improvement in the speed and quality of routine medical communication. Contamination of mobile phones can outweigh their potential benefit of using mobile phones in emergency situations, in ICU and would be detrimental to hospital hygiene (Fatma Ulger et al., 2009).

To provide preventive actions, it is essential to identify the reservoir of microorganisms that cause Nosocomial infections. This study is aimed to investigate the microbial contamination in daily used medical devices like Stethoscope, Blood pressure cuff and non medical devices such as mobile phones and to compare and estimate the microbial burden of Nosocomial infection in different areas of the hospital.

\section{Materials and Methods}

This cross sectional study was conducted in a Tertiary care Hospital over a period of six months. 150 medical and non-medical devices (stethoscopes-50, sphygmomanometers-50, mobile phones-50) of heath care providers including interns, doctors and nursing staff who frequently handle these devices were tested for the presence of pathogenic microorganisms.

Under aseptic precautions, sterile cotton tipped swab moistened with sterile normal saline $(0.9 \%)$ is wiped over the diaphragm of the stethoscope, inner and outer cuff of the blood pressure apparatus and the outer surface of the mobile phones.

Swabs are transported immediately to the microbiology laboratory and are inoculated in sheep Blood agar and MacConkey agar. After 24 hours of incubation at $37^{\circ} \mathrm{C}$, the organisms are identified with their colony morphology and biochemical parameters.

\section{Antibiotic Susceptibility Testing}

The isolated organisms were subjected to antimicrobial susceptibility testing with Kirby Bauer disc diffusion method as per CLSI Guidelines.

\section{Results and Discussion}

150 devices were tested for the presence of pathogenic microorganisms. Out of which 31 of them contained nosocomial pathogens. 11 out of 50 stethoscopes, 12 out of 50 mobile phones and 8 out of 50 sphygmomanometers were found to be positive for nosocomial pathogens

\section{Mobile Phones}

12 out of 50 mobile phones contained nosocomial pathogens. The pathogens isolated were Methicillin Resistant Staphylococcus aureus (MRSA), Methicillin Sensitive Staphylococcus aureus (MSSA), 
Acinetobacter, Micrococci, Pseudomonas and CONS.4 mobile phones had Micrococci (33\%) on them, 2 had MRSA(17\%), while 1 had MSSA(8\%).2 had CONS(17\%) while another two had Acinetobacter (17\%) and Pseudomonas (8\%) respectively.

\section{Sphygmomanometer}

Nosocomial pathogens were isolated from 8 out of 50 shygmomanometers. The pathogens isolated were Methicillin Sensitive Staphylococcus aureus, Klebsiella and CONS.4of the sphygmomanometers had CONS (50\%), while 3 had MSSA( $37 \%$ ) only one had Klebsiella(12.5\%).

\section{Stethoscopes}

Nosocomial pathogens were isolated from 11 out of 50 stethoscopes. The pathogens isolated were Methicillin Resistant Staphylococcus aureus (MRSA-27\%), Methicillin Susceptible Staphylococcus aureus (MSSA-9\%), Acinetobacter $(27 \%)$, Klebsiella (18\%), Micrococci (9\%) and Pseudomonas species (9\%).

MRSA and Acinetobacter were the common organisms isolated from stethoscopes. Micrococci and Staphylococcus aureus were the common nosocomial pathogens isolated from mobile phones and sphygmomanometers respectively.

The frequency of nosocomial pathogens varies in different medical devices such as stethoscopes, sphygmomanometers and in non medical devices such as mobile phones.

The nosocomial pathogens were identified, analysed and their antibiotic resistant pattern tabulated Most of the bacterial isolates were resistant to the commonly used antibiotics.
The transmission of infections in the hospital (nosocomial infections) from contaminated medical equipments and nonmedical devices is a major problem. The devices, if not sterilized/disinfected properly, may transmit microorganisms from one patient to the other.

\section{Mobile Phones}

$24 \%$ of mobile phones were isolated with nosocomial pathogens.

In concordance with the results, Ramesh et al., (2008) stated that $45 \%$ of mobile phones which were swabbed grew microorganisms. Similar results were also obtained by Goldblatt found, who found one fifth of the cellular phones used by HCWs harboured pathogenic microorganisms and may serve as vectors for health care transmission of microorganisms (Ramesh et al., 2008).

Higher rates of contamination was also reported by Brady et al., (2007) who showed that $89.7 \%$ of mobile phones were contaminated by bacteria. Micrococci was the most common organism isolated which may be due to the fact that it is the most common commensal of skin. 24\% of S.aureus isolated was Methicillin resistant, which is not concordant to the report of Tambekar et al., (2008) who stated that 95\% of mobile phones showed bacterial contamination and among the S.aureus isolates $83 \%$ were methicillin resistant.

MRSA isolates from mobile phones is in reality a serious worrisome issue. The HCW should be trained about the infection control measures like hand hygiene and disinfection of the mobile phones. Otherwise the use of mobile phones for communication during emergencies will be shadowed, and act as a nosocomial infection transmission device. 


\section{Sphygmomanometer}

As early as 1969 an Australian study identified the blood pressure cuff as a reservoir for bacteria, and that no other piece of hospital equipment was used more than without adequate disinfection (Beard, McIntyre and Roundtree, 1969). Hence it is a potential carrier of nosocomial pathogens in a health care set- up.

8 out of 50 blood pressure cuffs had pathogenic organisms, 4 cuffs contained CONS. MSSA was isolated from 3 cuffs while remaining one had Klebsiella. MSSA was also isolated from 8 out of 24 contaminted cuffs by Gupta, Walker and Cheesbrough (2006) who assessed the level of contamintion of blood pressure cuffs used in hospital wards (Khyati Jain et al., 2014).

50\% contained CONS which is in concordance to the results obtained by Gialluly who stated that most bacterial colonisation of BP cuffs corresponded to saprophytes of the skin flora (Coagulase Negative S.aureus.). No MRSA was isolated in contrast to a study by Webb (2002) using cultures taken from blood pressure cuffs found MRSA on $9 \%$ of the cuffs.

\section{Stethoscopes}

The results of our study revealed that the rate of contamination of nosocomial pathogens was $21 \%$ of 50 stehoscopes. Similar results have been obtained by a study by Alothman et al., had shown that $48 \%$ of the stehtoscopes were contaminted.

Higher levles were also reported. In a study by Gaur et al., out of a total of 58 diaphragms, 52(89.65\%) were colonised by bacteria (Bhatta et al., 2011), which is comparable to the observation of previous studies, which found that $71 \%$ to $100 \%$ of the stethoscopes were colonised by various bacteria (Kotsans et al., 2008).

Table.1 Total number of nosocomial pathogens isolated(n=150)

\begin{tabular}{|c|c|c|c|}
\hline Devices & $\begin{array}{c}\text { Total no of samples } \\
\text { obtained }\end{array}$ & $\begin{array}{c}\text { No. of samples with } \\
\text { nosocomial pathogens }\end{array}$ & Frequency \\
\hline Stethoscope & 50 & 11 & $21 \%$ \\
\hline Mobile phones & 50 & 12 & $24 \%$ \\
\hline Sphygmomanometer & 50 & 8 & $17 \%$ \\
\hline Total & 150 & 31 & $21 \%$ \\
\hline
\end{tabular}

Table.2 Frequency of nosocomial pathogens in Stethoscopes $(\mathrm{n}=50)$

\begin{tabular}{|c|c|c|}
\hline Nosocomial Pathogen & No. of organism & Frequency \\
\hline MRSA & 3 & $27 \%$ \\
\hline MSSA & 1 & $9 \%$ \\
\hline Acinetobacter & 3 & $27 \%$ \\
\hline Klebsiella & 2 & $18 \%$ \\
\hline Micrococci & 1 & $9 \%$ \\
\hline Pseudomonas species & 1 & $9 \%$ \\
\hline
\end{tabular}


Table.3 Common pathogens profile of the devices

\begin{tabular}{|c|c|}
\hline Devices & Most Common Pathogens \\
\hline Stethoscopes & MRSA, Acinetobacter $(27 \%)$ \\
\hline Mobile phones & Micrococci $(33 \%)$ \\
\hline Sphygmomanometers & Staphylococcus aureus $(37 \%)$ \\
\hline
\end{tabular}

Table.4 Resistant pattern of the microbial isolates

\begin{tabular}{|c|c|c|c|c|c|}
\hline Drugs & $\begin{array}{c}\text { S.aureus } \\
(\mathbf{n}-10)\end{array}$ & $\begin{array}{c}\text { Acinetobacter } \\
(\mathbf{n - 5})\end{array}$ & $\begin{array}{c}\text { Klebsiella } \\
(\mathbf{n - 3})\end{array}$ & $\begin{array}{c}\text { Pseudomonas } \\
(\mathbf{n}-2)\end{array}$ & $\begin{array}{c}\text { CONS } \\
(\mathbf{n}-6)\end{array}$ \\
\hline Ampicillin (10ug) & - & 60 & 66.7 & 100 & - \\
\hline Penicillin (10IU) & 100 & - & - & - & 100 \\
\hline Ciprofloxacin (5ug) & 30 & 40 & 33.3 & 0 & 33.3 \\
\hline Gentamycin (10ug) & 40 & 80 & 100 & 100 & 50 \\
\hline Amikacin (30ug) & 20 & 20 & 0 & 50 & 16.6 \\
\hline $\begin{array}{c}\text { Trimethoprim- } \\
\text { sulfamethoxazole } \\
(1.25 / 23.75 u g)\end{array}$ & 40 & 40 & 66.7 & 100 & 33.3 \\
\hline Cefotaxime (30ug) & - & & & & \\
\hline Cefoxitin (30ug) & 40 & - & - & 50 & - \\
\hline Tetracycline (30ug) & 30 & 40 & 33.3 & 100 & 30 \\
\hline Vancomycin (30ug) & 0 & - & - & - & 0 \\
\hline
\end{tabular}

Fig.1 Frequency of nosocomial pathogens in mobile phones

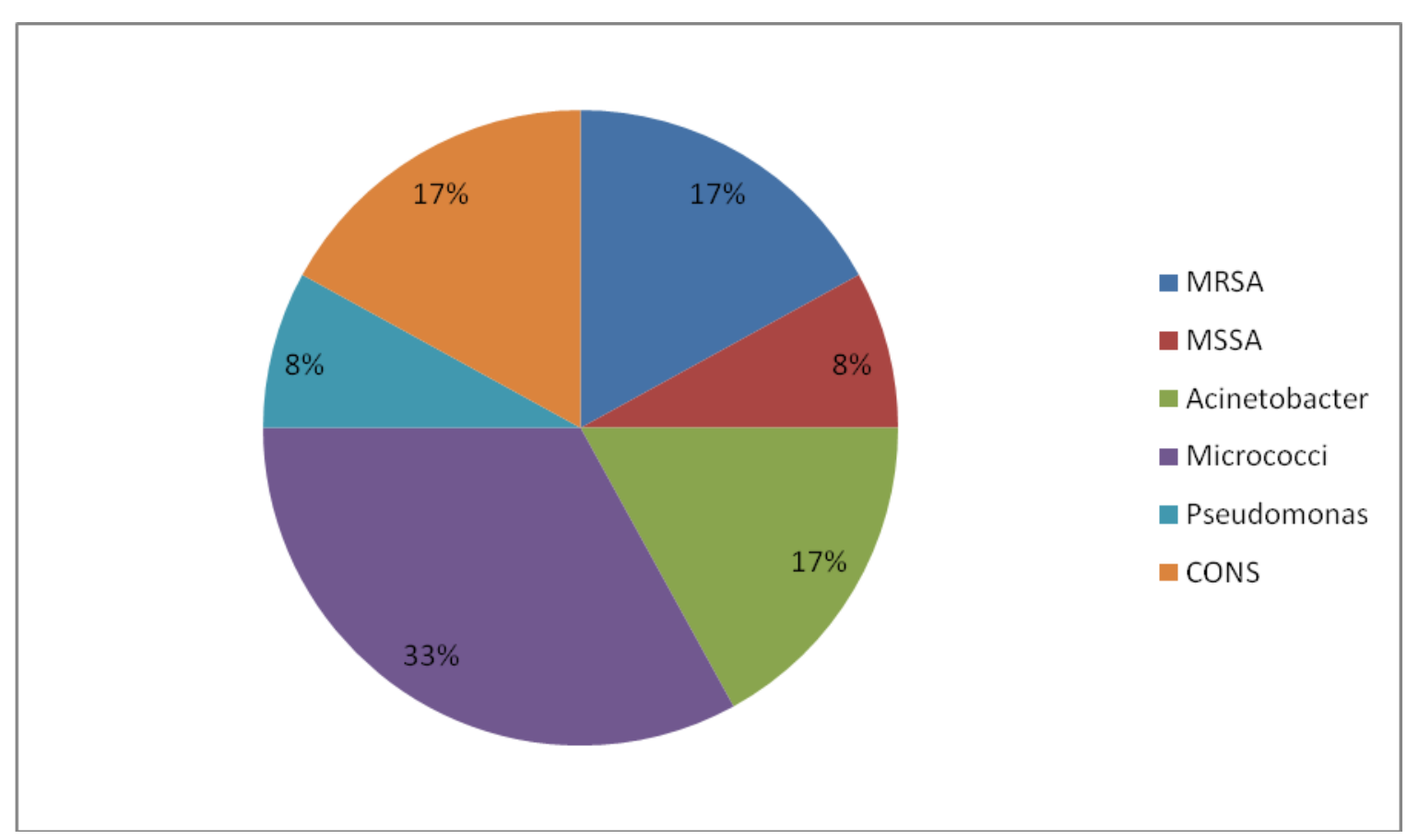


Fig.2 Frequency of nosocomial pathogens in Sphygmomanometer

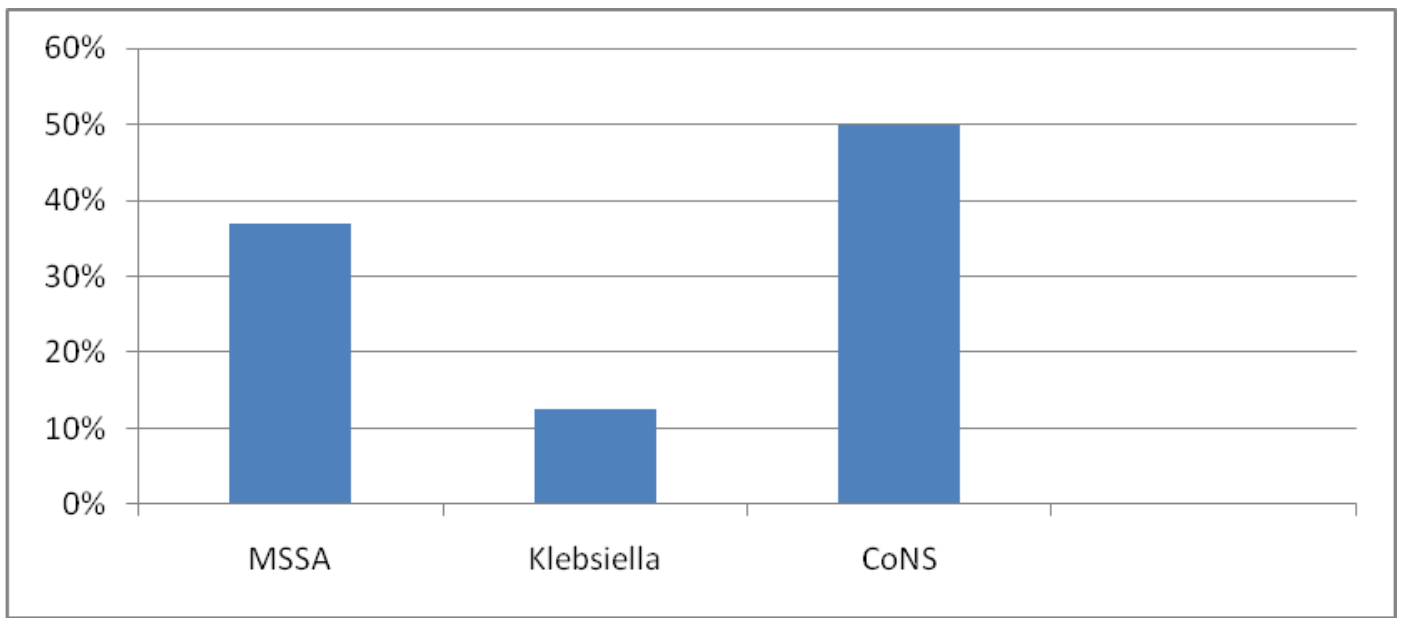

Fig.3 Frequency of nosocomial pathogens in different devices

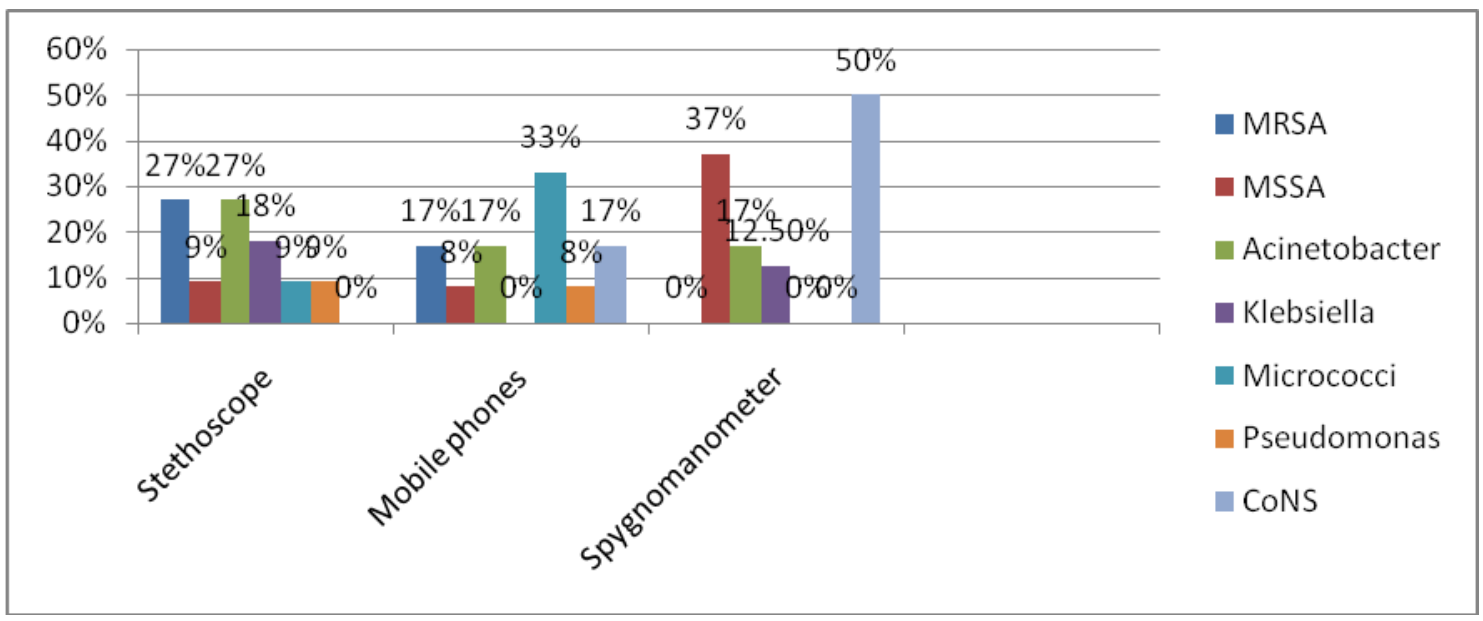

The most common organism isolated were MRSA and Acinetobacter. 4 other organisms were also isolated, out of which Micrococcus was $9 \%$ and no CONS were obtained, whereas Micrococcus species and CONS were the two most common isolates in the study of Gaur et al.

Nowadays disposable stethoscopes and covering silicone membrane over the stethoscope head to create a prophylactic barrier are various measures taken to prevent nosocomial infection spread by these devices, but is not feasible in a developing country like ours.
Health care personnels usually carry the stethoscopes around their necks and carry the contaminated device home which carries the risk of transmission of nosocomial pathogens to themselves and their family members.

In the present study $40 \%$ of Staphylococcus aureus and $50 \%$ of CONS isolated were Methicillin resistant. Among the isolates Pseudomonas was the most resistant organism which was $100 \%$ resistant to commonly used antibiotics such as gentamycin, cotrimoxazole and tetracycline. 
The present study reveals that it is mandatory to train healthcare personnel about strict infection control procedure, hand hygiene and environmental disinfection. Developing preventive strategies like routine decontamination of medical and non-medical devices with alcohol containing disinfectant materials might reduce cross-infection We could easily avoid spreading bacterial infections just by using regular cleansing agents and rearranging our environment. Training and motivating the HCWs in understanding the importance of infection control aspect and putting it into practice can be an important step in preventing nosocomial infection.

In conclusion, $21 \%$ of the 150 (medical and non-medical) devices used by the health care workers contained nosocomial pathogens. This highlights importance of stethoscopes, mobile phones and spygnomanometer as reservoirs of nosocomial pathogens and the associated risk of transmission of nosocomial infections to the patient and to the health care providers themselves. It calls for strenghtening of the infection control measures taken in the hospital and further surveillance of nosocomial pathogens must be undertaken at regular intervals to reduce the microbial burden in the devices.

\section{References}

Bhatta, D.R., Gokhale, S., Ansari, M.T., Tiwari, H.K., Gaur, A., Mathuria, J.M., Ghosh, A.N. 2011. Stethoscopes: A Possible Mode of Transmission of Nosocomial Pthogen .Department of Microbiology, Manipal College of Medical Sciences, Pokhara, Nepal. J. Clin. Diag. Res., 5(6): 1173-1176.

Brady, R.R., Fraser, S.F., Dunlop, M.G., Paterson-Brown, S., Gibb, A.P. 2007. Bacterial contamination of mobile communication devices in the operative environment. The Hosp. Infect. Soc., 10: 4-15.

De Gialluly, C., Morange, V., de Gialluly, E., Loulergue, J., van der Mee, N., Quentin, R. 2006. Blood pressure cuff as a potential vector of pathogenic microorganisms:A prospective study in a teaching hospital. From the Laboratory of Microbiology and Hospital Hygiene, University Hospital, Tours, France. Infect. Control Hosp. Epidemiol., 27(9): 940-3.

Dennis Schaberg, D.R., Culver, D.H., Gaynes, R.P. 1991. Major trends in the microbial etiology of nosocomial infection. Department of Internal Medicine, University of Michigan Medical Centre, Michigan, USA. Hospital infections programme, Centers for Disease Control, Atlanta, Georgia, USA. Am. J. Med., 16; 91(3B): 72S-75S.

Fatma Ulger, Saban Esen, Ahmet Dilek, Keramettin Yanik, Murat Gunaydin, Hakan Leblebicioglu. 2009. Are we aware how contaminated our mobile phones with nosocomial pathogens? Department of Anaesthesiology and Reanimation, Faculty of Medicine, OndokuzMayis University, Turkey. Annals of Clin. Microbiol. Antimicrobials, 8: 31.

Gopinath, K.G., Stanley, S., Malathi, E., Chandy, G.M. 2011. Pagers and stethoscopes as vehicles of potential nosocomial pathogens in a tertiary care hospital in a developing country.Hospital Infection Control Committee, Christian Medical College, Vellore. Trop. Doct., 41(1): 43-5.

Khyati Jain, Nilesh, S., Chavan and S.M. Jain. 2014. Blood Pressure Cuff - As a Fomite for cross infection. Int. J. Curr. Microbiol. App. Sci., 3(6): 755-758.

Kotsans, D., Scott, C., Gillespie, E.E., 
Korman, T.M. 2008. What's haning around your neck? Pathogenic bacteria on identity badges and lanyards. Med. J. Australia, 188: 5-8.

Ramesh, J., Carter, A.O., Campbell, Mh, et al. 2008. Use of mobile phones by medical staff at Queen Elizabeth Hospital, Barbados: evidence for both benefit and harm. J. Hosp. Infect., 70:
160-165.

Srikanth, P., Ezhil, R., Suchitra, S., Anandhi, I., Maheswari, U., Kalyani, J. 2008. The mobile phone in a tropical setting emerging threat for infection control; $13^{\text {th }}$ International Congress on Infectious Diseases Abstracts, Poster Presentations, 10: 273.

\section{How to cite this article:}

Balapriya, P., J. Padmakumari and Vijayalakshmi, A. 2016. Screening for Nosocomial Pathogens in Stethoscopes, Sphygmomanometers and Mobile Phones of Health Care Providers in a Teritiary Care Hospital. Int.J.Curr.Microbiol.App.Sci. 5(10): 91-98. doi: http://dx.doi.org/10.20546/ijcmas.2016.510.011 